\begin{tabular}{ccc}
\hline & International Journal of Engineering \& Technology, $7(2.33)(2018) 315-318$ \\
SPC & Website w ww.sciencepubco.com/index.php/IJET \\
Research paper & Technology \\
\hline
\end{tabular}

\title{
A study on damage to mechanical seat cushion made from different materials of extension frame
}

\author{
Jae Won Kim ${ }^{1}$, Jae Ung $\mathrm{Cho}^{2}$, Chan Ki Cho ${ }^{3}$, Jin Oh Kim ${ }^{3}$ \\ ${ }^{1}$ Department of Mechanical Engineering, l, Kongju National University, 1223-24, Cheonan Daero, Seobuk-gu, Cheonan-si Chung- \\ nam,31080, Korea \\ ${ }^{2}$ Division of Mechanical \& Automotive Engineering, Kongju National University, 1223-24, Cheonan Daero, Seobuk-gu, Cheonan- \\ Si Hungnam, 31080, Korea \\ ${ }^{3}$ R\&D, Daechang Seat Co., LTD., 26-8, Oedongnonggongdanji-gil, Oedong-eup, Gyeongju-si, Gyeongsangbuk-do, Republic of Korea \\ *Corresponding author E-mail: jucho@kongju.ac.kr
}

\begin{abstract}
Background/Objectives: : Automotive seat is a very important component to prevent accidents by reducing passenger's tiredness, thus, this study worked on analyzing damage with different materials of extension frames of mechanical seat cushions.

Methods/Statistical analysis: In this study, we performed an experiment on cushion extension frames by splitting it into two parts. We studied about the damage prediction of slave body for each material property of ABS, PP, PLA, and PA6.6. For analyzing the condition, we assigned the side part of the master body for fixed support, and we progressed on analysis by applying with $690 \mathrm{~N}$ on the entire part of the slave body.

Findings: This research worked on the study of damage to different materials of extension frames of seat cushions. After confirming the stress equivalence of the entire model for each material, PP showed the highest equivalent stress of 180.88MPa, and ABS showed the lowest equivalent stress of 151.73MPa. Overall, we could see that in the order of ABS, PA6.6, PLA, PP have a higher tendency to be broken. In addition, when confirming equivalent stress of master body depending on materials of slave body, PA6.6 showed the highest equivalent stress of $166.3 \mathrm{MPa}$, and $\mathrm{ABS}$ showed the lowest equivalent stress of $124.06 \mathrm{MPa}$. Overall, we could see that in the order of ABS, PP, PLA and PP6.6 have a higher tendency to be broken. In comparing shear stress on the gear part, which has the highest tendency to be broken in among the entire model, depending on the material of the slave body, PLA showed the greatest shear stress of 88.945MPa, and ABS showed the lowest shear stress of 69.766MPa.

Improvements/Applications: This study worked for the improvements and applications of cushion extension frames as the securement of material by investigating these factors.
\end{abstract}

Keywords: Seat Frame; Cushion Extension; Fatigue; Equivalent Stress; Passenger

\section{Introduction}

Although the power-train, that is, the engine and power transmission gear play an important role in components for automobile, there are many other parts that consists of a car. Among those components, the researches about seats, which have the closest connection to drivers, have been done the most. Seats are always related with drivers and passengers, which means it is directly connected to the drivers and passenger's tiredness level. To reduce drivers' tiredness, a lot of studies are being done about lumbar support for supporting the lumbar of drivers, side bolsters to hold the driver's body at sharp corners, and warm or cool seats to adjust the driver's condition in hot or cold weather. In this study, we worked on research on extension framed of cushions that are able to adjust the length of the seat cushion to the driver's legs, and analyzed the results about damage from weight and impact depending on the material [1-8].

\section{Materials and methods}

Different forms in Figure 1 were used for this study of damage depending on materials of mechanical extension frames of seats.

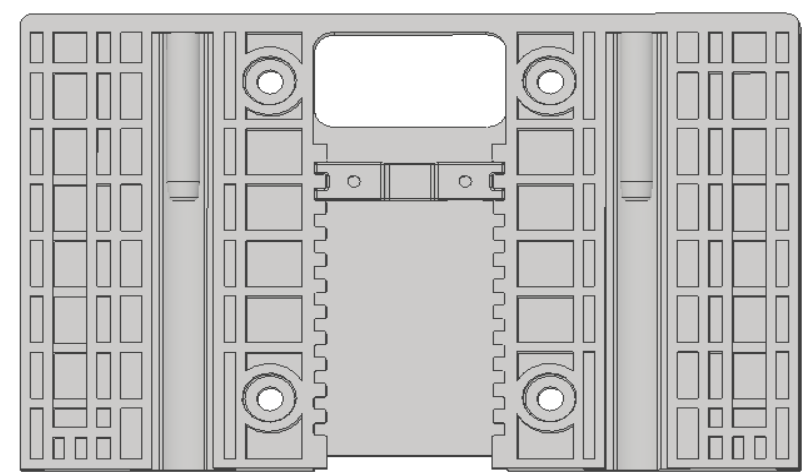

Fig. 1: Forms of the Entire Model. 


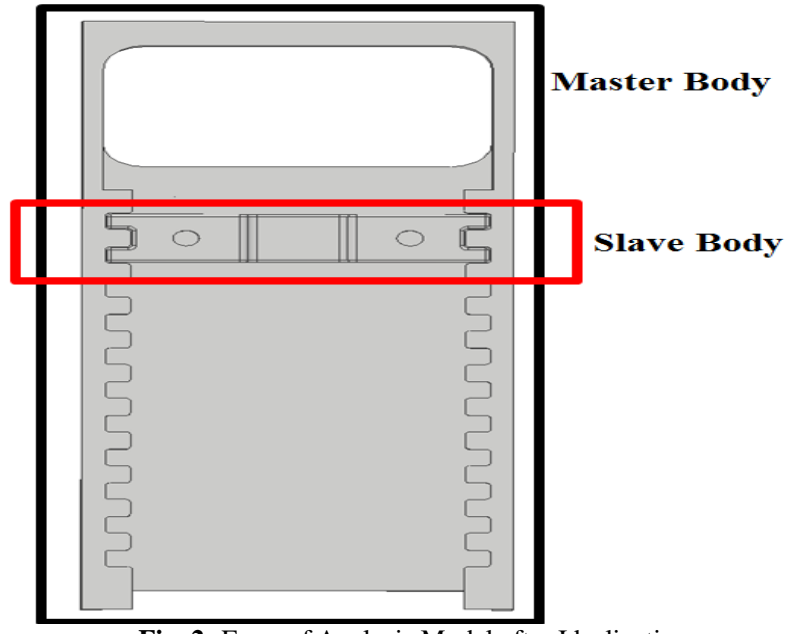

Fig. 2: Form of Analysis Model after Idealization.

We designed Figure 1 using CATIA, and Figure 2 is an idealized model to increase the convergence of analysis result and reduce occurrence of stress singularity for analyzing Figure 1. For that reason, the analysis has been carried after the unnecessary parts were revised.

Table 1:Material Properties

\begin{tabular}{|c|c|c|c|c|c|}
\hline Material & PLA & PP & PA6.6 & ABS & $\begin{array}{l}\text { Resin } \\
\text { Epoxy }\end{array}$ \\
\hline Density(kg/m3) & $\begin{array}{l}1.29 \mathrm{e} \\
+12\end{array}$ & $9.33 e+11$ & $1.15 \mathrm{e}+12$ & $1.07 e+12$ & $\begin{array}{l}1.16 \mathrm{e}- \\
7\end{array}$ \\
\hline $\begin{array}{l}\text { Young's } \\
\text { Modulus (MPa) }\end{array}$ & 2 & 1760 & 1650 & 2320 & 3780 \\
\hline Poisson's Ratio & 0.3 & 0.16 & 0.38 & 0.38 & 0.35 \\
\hline $\begin{array}{l}\text { Yield strength } \\
(\mathrm{MPa})\end{array}$ & 44.8 & 32 & 5.5 & 43.3 & 54.6 \\
\hline $\begin{array}{l}\text { Ultimate } \\
\text { strength }(\mathrm{MPa})\end{array}$ & 50.1 & 30.1 & - & 38.4 & - \\
\hline
\end{tabular}

Table 1 shows the properties of materials used for analysis. Master body, which is related with seat frame, is assigned with resin epoxy, and slave body, which is detached to the master body, is assigned with poly amide of PA6.6, polypropylene (PP), poly lactic acid(PLA), acrylonitrile butadiene styrene(ABS) to see the tendency of damage depending on materials. Table 2 shows the weight of slave body with different materials [9-15].

Table 2: Weight of Slave Body with Different Materials

\begin{tabular}{lllll}
\hline Material & PLA & PP & PA 6.6 & ABS \\
\hline Weight $(\mathrm{g})$ & 188 & 136 & 167 & 156 \\
\hline
\end{tabular}

\section{Boundary conditions}

Figure 3 is the condition for analyzing this study. We applied the side of the master body with fixed support and assigned a bolt fixation area of the slave body with force, and confirmed the damage at the contact area. The pressure of $690 \mathrm{~N}$ is given to describe the force of $70 \mathrm{~kg}$. We observed the break tendency giving this condition to each material of the slave body.

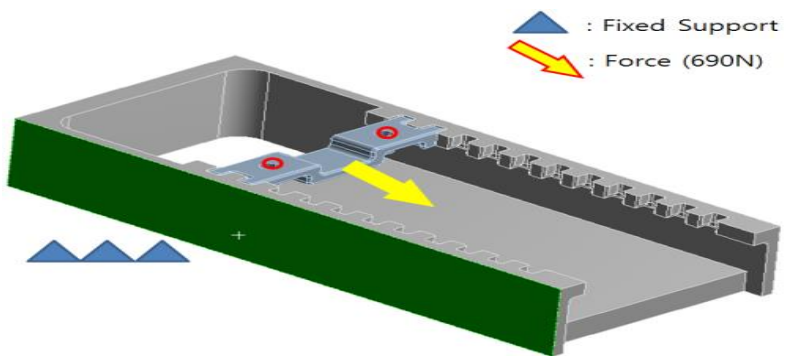

Fig. 3: Analysis Condition of Extension Frame of Seat Cushion.
In this research, we analyzed the methods above to study the damage of extension frames of mechanical seat cushions depending on materials, and the results are as follows

\section{Simulation analysis results}

In this research, we analyzed the methods above to study the damage of extension frames of mechanical seat cushions depending on materials, and the results are as follows.

(A)PP
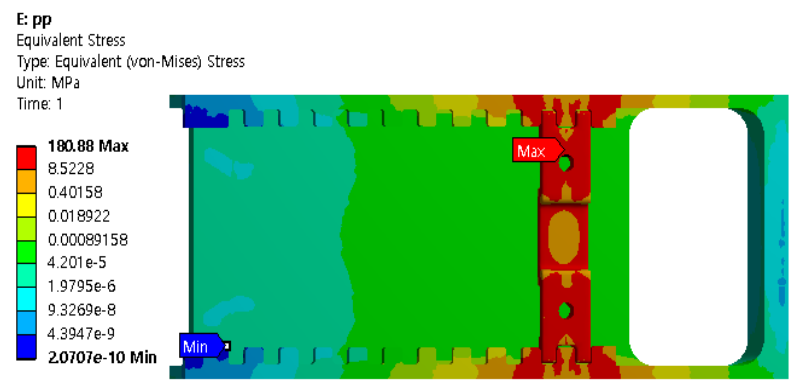

(B)PA 6.6

A: $+690 \mathrm{~N}$

Equivalent Stress

Type: Equivalent (von-Mises) Stress

Unit: $M P_{a}$

Time: 1

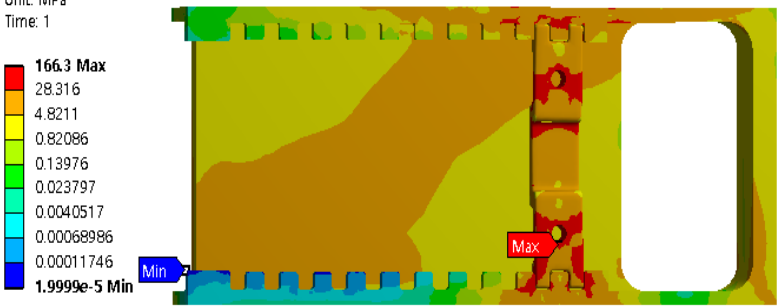

.99990-5 Min

F: abs

(C)ABS

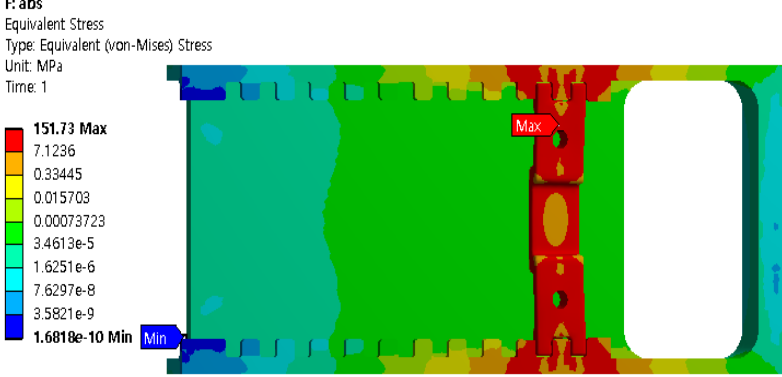

(D)PLA

G: pla

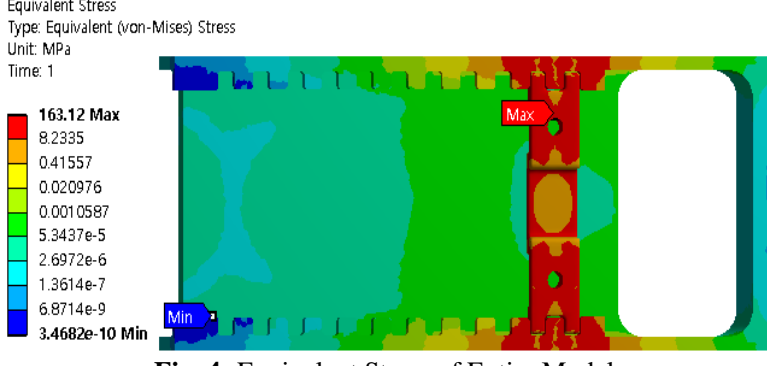

Fig. 4: Equivalent Stress of Entire Model.

Figure 4 is the equivalent stress of the entire models, and we could check the equivalent stress of the slave body depending on materials. Considering a contour of the entire equivalent stress, the highest stress was shown at the gear part identically for the damaged area of the entire model. Considering a contour of the entire equivalent stress, the highest stress was shown at the gear identically for the damaged area of the entire model. PP scored 180.88MPa of stress, and finally $163.12 \mathrm{MPa}$ for PLA. Based on 
these results, in the order of ABS, PA6.6, PLA, PP showed low damage.

(A)PP
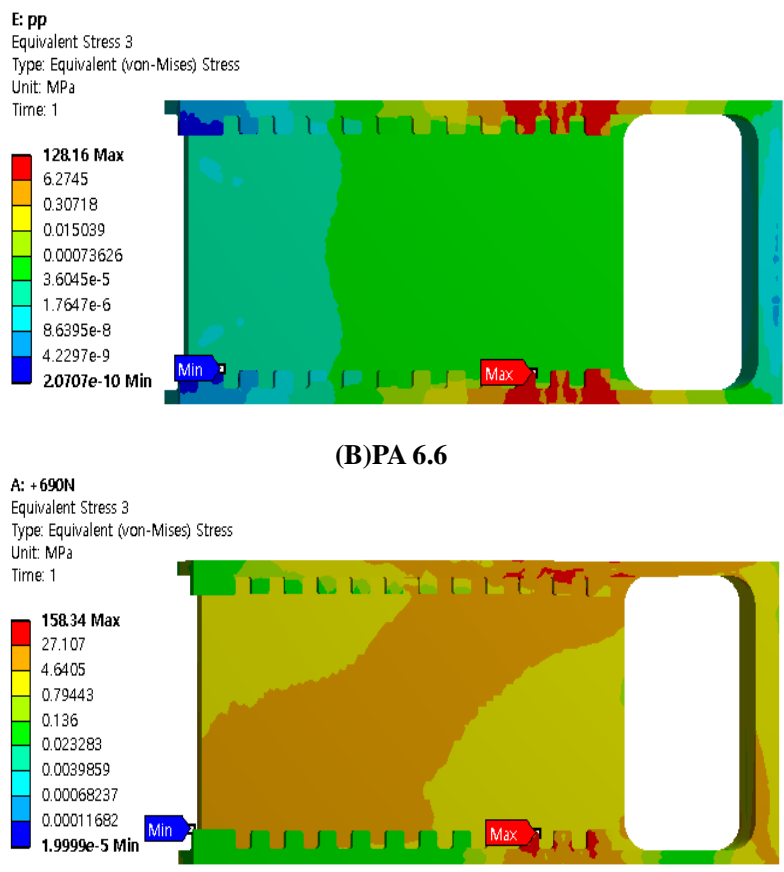

(C)ABS

F: abs
Equivalent Stress 3

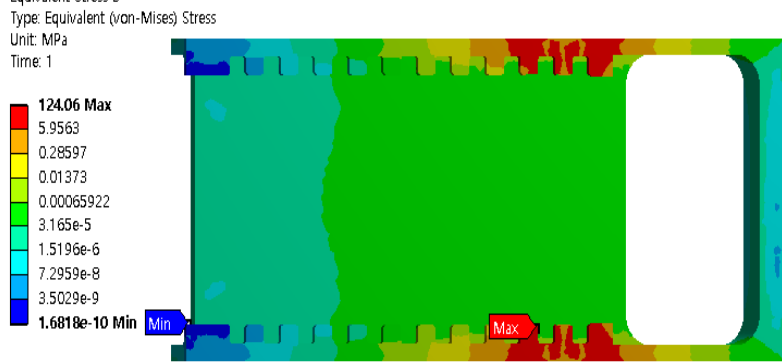

(D)PLA

G: pla

Equivalent Stress 3

Type: Equivalent (von-Mises) Stress

Unit: $\mathrm{MPd}$

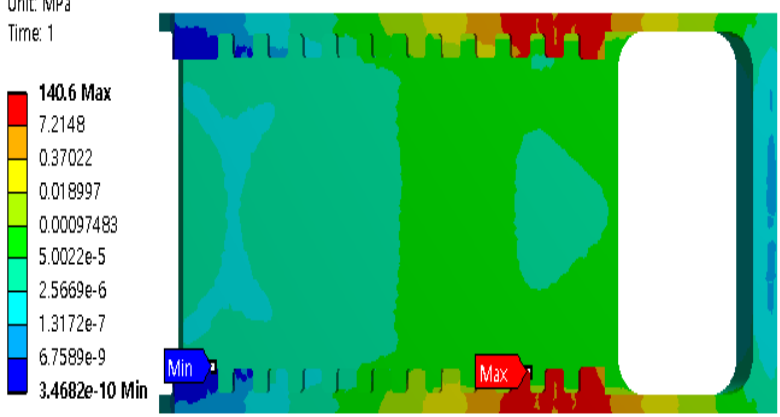

Fig. 5: Equivalent Stress of Master Body.

Figure 5 is the equivalent stress of the master body and we could confirm the equivalent stress of the master body depending on materials of the slave body. When we verified the contour of the entire equivalent stress, the highest stress was shown at the gear for damaged area that is in contact with the slave body. For verifying the equivalent stress of the slave body depending on materials, PA6.6 showed 166.3MPa and ABS showed 124.06MPa. PP scored $128.16 .88 \mathrm{MPa}$ of stress, and lastly $140.6 .12 \mathrm{MPa}$ for PLA. Based on these results, in the order of ABS, PP, and PLA, PA6.6 showed the low damage on master body when they are assigned for the materials of the slave body.
(A)PP

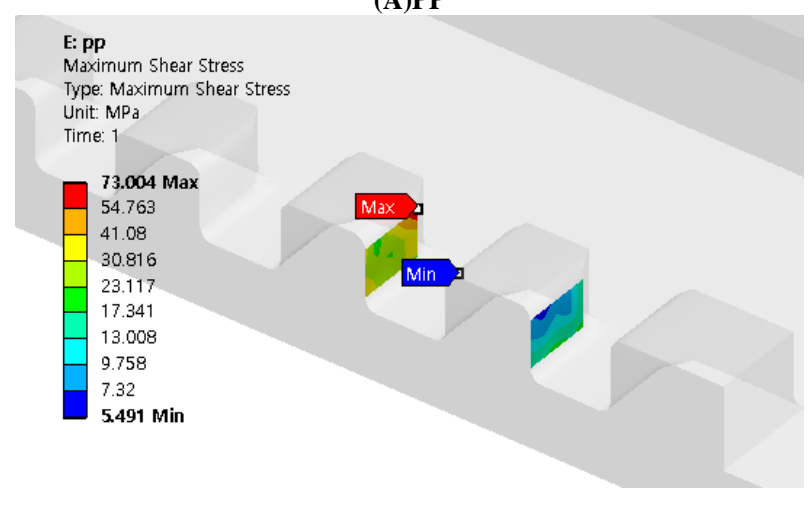

(B)PA 6.6

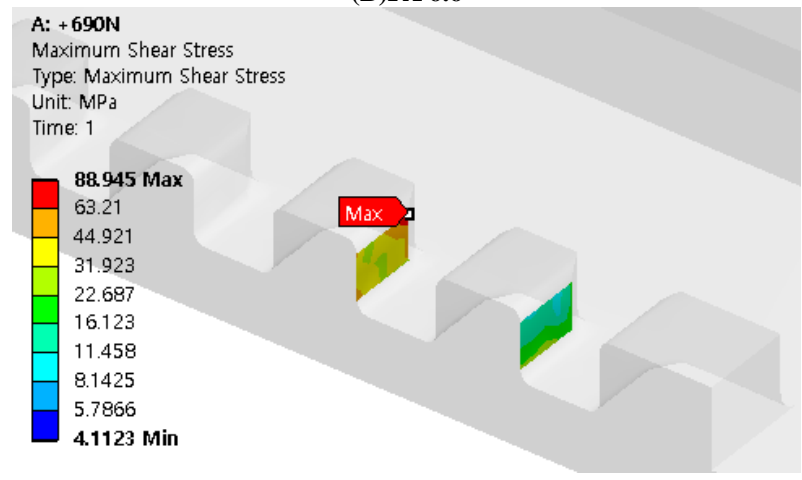

(C)ABS

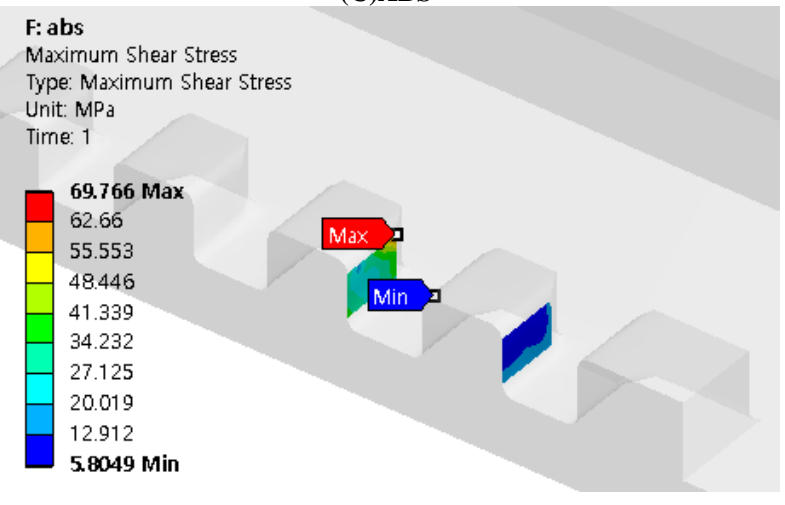

(D)PLA

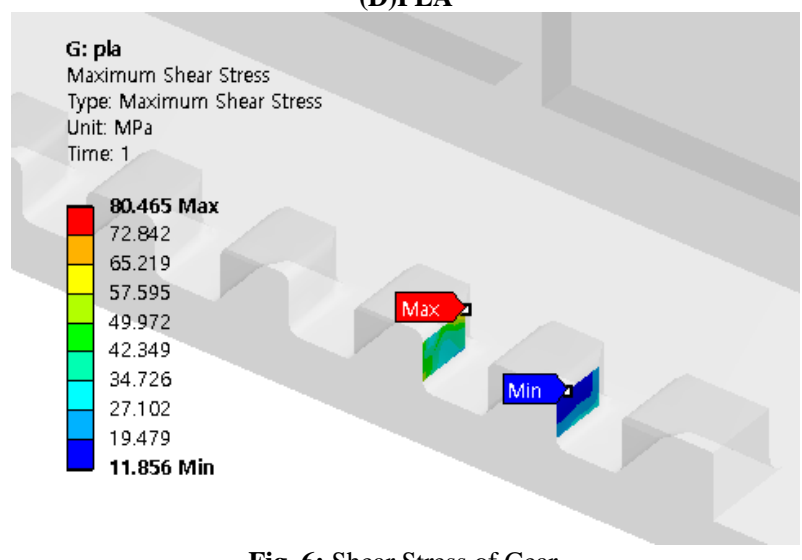

Fig. 6: Shear Stress of Gear.

Figure 6 verified the maximum shear stress to check damage on the gear of which was the part with the highest equivalent stress of master body. For the results, the shear stress of $88.945 \mathrm{MPa}$ was shown when the material of slave body was PA6.6. Additionally, ABS, the other material, showed the shear stress of 69.766MPA, PP showed 73.004MPa, and PLA showed 80.465MPa. Based on this result, we could see the shear stress of master body depending on the material of slave body at the gear part. 


\section{Conclusions}

This research studied the damage of extension of mechanical seat cushions depending on materials of the Slave Body, and PA6.6, ABS, PP, and PLA were designated for materials of the Slave Body. The results are as follows.

1) The most highly damaged area in common among the entire model is the part where the master body and slave body meet.

2) Verifying the equivalent stress of the extension frame of the mechanical seat depending on the materials of slave body, PP showed the highest stress with $180.88 \mathrm{MPa}$, and ABS showed the lowest stress with 151.73MPa. Overall, we could see that in the order of ABS, PA6.6, and PLA, PP has a higher tendency to be broken.

3) PP is the lightest model of slave body, which is $136 \mathrm{~g}$. However, comparing the weight to stress, PP showed the lightest weight against the stress occurrence.

4) Observing equivalent stress of master body of extension frame of mechanical seat depending on slave body, PA6.6 showed the highest stress of 166.3MPa and ABS showed the lowest stress of $124.06 \mathrm{MPa}$. Overall, we could see that in the order of ABS, P.P, and PLA, PP6.6 has a higher tendency to be broken.

5) Comparing the shear stress depending on the materials of slave body at the gear part, which is the most severely damaging part in common in entire model, PLA showed the biggest shear stress of $88.945 \mathrm{MPa}$ and ABS showed the lowest shear stress of $69.766 \mathrm{MPa}$.

6) Based on the results above, the study on the damage of extension frames of mechanical seat cushions depending on materials is processed and through these factors, it is considered that we can secure the design factor of cushion extension frames.

\section{Acknowledgment}

This work was (partly) supported by Advanced Motor Parts Regional Innovation Center (AMPRIC) of Kongju National University administered by MSS(Ministry of SMEs and Startups), Korea.

\section{References}

[1] Heo, U., Kim, S. K., Song, M. J., Yang, I. Y. \&Im, K. H., (2011). Effectiveness evaluation for seat parts by seat belt anchorage strength analysis. International Journal of Precision Engineering and Manufacturing, 12(6), 1031-1034.

[2] Jo, H. C. \& Kim, Y. E. (2009). A study on the influence of the seat and head restraint foam stiffnesses on neck injury in low speed offset rear impacts. International Journal of Precision Engineering and Manufacturing, 10(2), 105-110

[3] Kim, H. S., Lee, Y. S., Yang, S. M. \& Kang, H. Y., (2016). Structural analysis on variable characteristics of automotive seat frame by FEA. International Journal of Precision Engineering and Manufacturing-Green Technology, 3(1), 75-79.

[4] Jung, K. W., Kawahito, Y. \& Katayama, S. (2014).Mechanical Property and Joining Characteristics of Laser Direct Joining of CFRP to Polyethylene Terephthalate. International Journal of Precision Engineering and Manufacturing-Green Technology,1(1), 4348.

[5] Kim, J. H., Ra, S. W., Kim, H. S. \& Kim, J. H. (2015). On Clamping Force Characteristics in M1.4, Subminiature Screw for CFRP Stacking Angles. International Journal of Precision Engineering and Manufacturing, 32(6), 517-521.

[6] Brogioli, M., Gobbi, M., Mastinu, G. \& Pennati, M. (2011). Parameter Sensitivity Analysis of a Passenger/Seat Model for Ride Comfort Assessment. Experimental Mechanics, 51(8), 1237-1249.

[7] Yang,J. T., Choi,H. Y., Lee,J. H.\& Lee,S. U. (2014). Empirical analysis on the effect of design variables of automotive seat lumbar support on the initial sitting discomfort. International Journal of Automotive Technology, 15(4), 667-672

[8] Yang, J. Y. \& Jeon, S. S. Analytical models for the initial stiffness and plastic moment capacity of an unstiffened top and seat angle connection under a shear load, International Journal of Steel Structures, 2009, 9(3), pp. 195-205.

[9] Jo, H. C. \& Kim, Y. E. (2009). A study on the influence of the seat and head restraint foam stiffnesses on neck injury in low speed offset rear impacts. International Journal of Precision Engineering and Manufacturing, 10(2), 105-110.

[10] Zheng, E., Fan, Y., Zhu, R., Zhu, Y. \& Xian. J. (2016). Prediction of the vibration characteristics for wheeled tractor with suspended driver seat including air spring and MR damper. Journal of Mechanical Science and Technology, 30(9), 4143-4156.

[11] Park, D. W. \& Yoo, W. S. (2009). A study on the design of a child seat system with mutipoint restraints to enhance safety. Journal of Mechanical Science and Technology, 23(12), 3316-3322.

[12] Song, Y. J., Yang, I. Y., Im, K. H., Ma, Z., Zhao, H., Lu, S., Li, H.\& Liu, C. (2016). Method for determining the true stress of cross-shaped specimens subjected to biaxial tensile loads. Instruments and Experimental Techniques, 59 (2), 287-293.

[13] Mizuno, K., Iwata, K.,Namikiri, T. \& Tanaka, N. (2006). FE Analysis of Human Model and Crash Dummy Response in Various Child Restraint Systems. Transactions of the Society of Automotive Engineers of Japan, 37(6), 193-198.

[14] Mao, J., Wang, W., Zhang, J. \& Liu, Y. (2015). Numerical investigation on the dynamic behaviors of turbine valve disc-seat impact at low velocity. Journal of Mechanical Science and Technology, 29(2), 507-515.

[15] Zhang, Y., Jiang, S., Zhao, Y. \& Shan, D. (2014). Isothermal precision forging of aluminum alloy ring seats with different preforms using FEM and experimental investigation. The International Journal of Advanced Manufacturing Technology, 72(9-12), 1693-1703. 